\title{
openheart Antioxidant bilirubin works in multiple ways to reduce risk for obesity and its health complications
}

\author{
James J DiNicolantonio, ${ }^{1}$ Mark F McCarty, ${ }^{2}$ James H O’Keefe ${ }^{1}$
}

To cite: DiNicolantonio JJ, McCarty MF, O'Keefe JH. Antioxidant bilirubin works in multiple ways to reduce risk for obesity and its health complications. Open Heart 2018;5:e000914. doi:10.1136/ openhrt-2018-000914

Accepted 26 September 2018

Check for updates

\section{(c) Author(s) (or their} employer(s)) 2018. Re-use permitted under CC BY-NC. No commercial re-use. See rights and permissions. Published by BMJ.

${ }^{1}$ Department of Preventive Cardiology, Saint Luke's Mid America Heart Institute, Kansas City, Missouri, USA

${ }^{2}$ Catalytic Longevity, San Diego, California, USA

Correspondence to Dr James J DiNicolantonio; jjdinicol@gmail.com

\section{UNCONJUGATED BILIRUBIN FUNCTIONS PHYSIOLOGICALLY TO INHIBIT NADPH OXIDASE COMPLEXES}

Gilbert syndrome (GS) is a common genetic variant in which plasma unconjugated bilirubin levels are elevated throughout life, in the absence of hepatic pathology. ${ }^{1}$ This typically reflects decreased hepatic capacity for conjugation of bilirubin coupled with an upregulation of bilirubin generation. Typically, subjects with GS are homozygous for promoter mutations compromising transcriptional efficiency in the gene coding for uridine-diphosphoglucuronate glucuronosyltransferase 1A1 (UGT1A1), which links bilirubin to glucuronic acid; as a result, hepatic expression of this enzyme is decreased, although the enzyme itself is functionally normal. However, plasma bilirubin levels in many people homozygous for such mutations fail to exceed the level (defined as either 17.1 or $20 \mu \mathrm{mol} / \mathrm{L}$ ) considered diagnostic for GS. Hence, subjects with GS also are characterised by an increased rate of bilirubin generation, ultimately traceable to increased heme synthesis. In some cases, this may reflect upregulated heme oxygenase activity, which would reflexly boost heme production. ${ }^{12}$

Epidemiological studies have found that GS confers potent and versatile health protection. ${ }^{2-5}$ Notably, an analysis of the Health Improvement Network primary care database in the UK found that, after adjustment for pertinent covariants, a diagnosis of GS was associated with a relative risk for all-cause mortality of 0.5 (95\% CI 0.4 to 0.7 ; $\mathrm{p}<0.001){ }^{6}$

This remarkable health benefit appears likely to stem largely from the fact that physiological intracellular levels of unconjugated bilirubin inhibit certain common isoforms of NADPH oxidase. ${ }^{7-11}$ These membranebound superoxide-generating complexes are a major source of the oxidants that drive or exacerbate a high proportion of health disorders. Bilirubin's inhibitory impact on NADPH oxidase activity presumably explains much of the profound antioxidant activity of heme oxygenase, which cleaves heme to yield biliverdin, carbon monoxide and free iron; biliverdin is then rapidly reduced by the ubiquitously expressed enzyme biliverdin reductase to yield bilirubin. Expression of inducible form of heme oxygenase, HO-1, can be boosted by oxidative stress-often derived from NADPH oxidase activity; the resultant production of bilirubin feeds back to quell this oxidative stress. ${ }^{10}$ Although bilirubin can also act as a direct oxidant scavenger, its physiological intracellular level-in the low nanomolar range-is too low to compete in this regard with other intracellular scavengers (eg, glutathione, ascorbate) present in millimolar concentrations. ${ }^{3}$

While there currently is a common perception among medical scientists, rooted in the disappointing results of clinical trials with nutritional scavenging antioxidants such as ascorbate, alpha-tocopherol and beta-carotene, that antioxidants have limited potential for conferring health protection, this perception fails to grasp the crucial difference between scavenging antioxidants and 'source antioxidants', of which bilirubin is a key example. ${ }^{12}$ Source antioxidants, by definition, prevent oxidant production by suppressing superoxide generation at its source; they therefore oppose the often proinflammatory effects of hydrogen peroxide on cellular signalling, and prevent conversion of (often protective) nitric oxide to the potent oxidant peroxynitrite ${ }^{13} 14$-effects which scavenging antioxidants cannot achieve. Statins and angiotensin II antagonist drugs likewise can function as source antioxidants in vascular 
tissues by inhibiting the activation of certain NADPH oxidase complexes. ${ }^{12} 1516$

\section{MIMICKING GS AS A CLINICAL ANTIOXIDANT STRATEGY}

Although oral administration of bilirubin as a clinical strategy is not feasible, owing to its extremely low water solubility, plasma and tissue bilirubin levels can be increased by drugs or nutraceuticals that inhibit UGT1A1; this approach has been dubbed 'iatrogenic Gilbert syndrome'. 17 Alternatively, bilirubin's much more soluble precursor biliverdin could be administered orally. ${ }^{18}$ While biliverdin is a complex molecular quite expensive to synthesise, and no rich natural sources exist, the biliverdin metabolite phycocyanobilin (PhyCB) functions as a light-harvesting chromophore in cyanobacteria and certain blue-green algae, such as the food spirulina; PhyCB can constitute $0.6 \%$ or more of the dry weight of spirulina. ${ }^{19}$ PhyCB is readily converted by biliverdin reductase to the bilirubin analogue phycocyanorubin, which appears to share bilirubin's ability to inhibit NADPH oxidase complexes. ${ }^{19-21}$ Arguably, this may largely explain the versatile antioxidant and anti-inflammatory properties of oral spirulina (or of phycocyanin, the spirulina protein to which PhyCB is covalently attached) in rodent studies. ${ }^{192223}$ Hence, spirulina-or, preferably, spirulina extracts enriched in PhyCB, since spirulina itself has an unappetising flavour and odour-may have considerable potential as source antioxidants.

\section{GS IS ASSOCIATED WITH LOWER GAIN IN FAT MASS DURING LATER LIFE}

A recent cross-sectional epidemiological study evaluating subjects with GS has discovered that GS is associated with a reduced tendency to gain body fat in later life. ${ }^{24}$ The study enrolled 124 subjects with GS (average plasma unconjugated bilirubin $30.7 \mu \mathrm{M}$ ) and 124 age-matched and gender-matched controls $(8.7 \mu \mathrm{M})$. Unlike previous studies evaluating Body Mass Index (BMI) in subjects with GS — which found modestly lower BMI as compared with age-matched controls ${ }^{25}$ - this study was designed to analyse young subjects (under 35) and older subjects (over 35) separately. Whereas, as compared with age/ gender-matched controls, the subjects with GS in the younger group were found to have a modestly but significantly lower BMI (22.5 vs 23.5), the disparity for the older group was dramatic-23.8 vs $27.2(\mathrm{p}<0.001)$. Moreover, the average body fat content in the older GS group was $21.8 \%$, as compared with $29.3 \%$ in their controls $(\mathrm{p}<0.01)$. A reasonable deduction is that chronically elevated free unconjugated bilirubin-and perhaps an upregulation in intracellular bilirubin generation-somehow opposes age-related gain in body fat.

Of related interest is a study showing that intraperitoneal administration of bilirubin-administered daily for 14 days-inhibits weight gain in rats fed a diet high in fats and sugar. ${ }^{26}$ Bilirubin injections were also found to prevent deterioration of glucose tolerance. A trend towards decreased calorie consumption in the bilirubin-treated rats just failed to achieve statistical significance $(\mathrm{p}=0.06)$.

A credible case can be made that the favourable impact of elevated bilirubin on risk for undesirable weight gain reflects preservation of hypothalamic leptin sensitivity. ${ }^{27}$ Rodents rendered obese with high-fat, high-sugar 'Western' diets develop leptin resistance in the arcuate nucleus of the hypothalamus; for this reason, as the rodents become obese, the evolving hyperleptinemia fails to oppose the hyperphagia induced by such diets. ${ }^{28-30}$ This leptin resistance is mediated, at least in part, by activation and proliferation of microglia in the arcuate nucleus, which can produce cytokines (notably tumour necrosis factor- $\alpha^{31}$ that counteract leptin signalling) ${ }^{32-34}$ Activation of NADPH oxidase is a key mediator of pro-inflammatory microglial activation ${ }^{35-37}$; hence, elevated bilirubin might be expected to support effective leptin function in the arcuate nucleus, thereby aiding appetite control. $^{27}$

\section{BILIRUBIN ACTS ON ADIPOCYTES TO COUNTER METABOLIC SYNDROME}

Oxidative stress in adipocytes, stemming largely from NADPH oxidase activity, appears to play a key role in the induction of insulin resistance and the skewing of adipokine and cytokine production in hypertrophied adipocytes. $^{38-43}$ Hence, bilirubin and heme oxygenase activity could be expected to aid maintenance of adipocyte insulin sensitivity. Indeed, plasma levels of unconjugated bilirubin have been found to correlate inversely with risk for metabolic syndrome and diabetes in prospective epidemiological studies, as confirmed in a recent meta-analysis. ${ }^{44}$

In both cross-sectional and prospective studies, higher plasma bilirubin levels are associated with better insulin sensitivity and decreased risk for metabolic syndrome and type 2 diabetes-independent of BMI. ${ }^{45}$ Hence, bilirubin may function both to prevent adipocyte hypertrophy-via its hypothalamic effects-and to improve the function of adipocytes that have already hypertrophied.

A direct protective effect of bilirubin on adipocyte function may be largely responsible for this phenomenon. Hypertrophied insulin-resistant adipocytes are characterised by increased oxidative stress, derived in large part from NADPH oxidase complexes (Nox2 and Nox4 dependent); the activated macrophages in hypertrophic visceral adipose tissue (expressing Nox2) can also contribute to this oxidant load. ${ }^{39-4147}$ There is considerable evidence that this oxidant stress plays a mediated role in the insulin resistance, upregulation of proinflammatory cytokines and diminished adiponectin secretion characteristic of hypertrophied visceral adipocytes.

Adverse effects of oxidants on adipocyte function may be mediated in large part by increased activation of the ASK1-MKK4-JNK signalling pathway. ${ }^{48}$ Activation of JNK in hypertrophied adipocytes plays a central role in 
metabolic syndrome. ${ }^{49}{ }^{50}$ Adipocyte-specific expression of dominant-negative JNK prevents systemic insulin resistance, glucose intolerance and hepatic steatosis in mice fed a high-fat diet. ${ }^{50}$ Moreover, this prevents the decline in adiponectin production, the increase in pro-inflammatory cytokines and the infiltration of activated macrophages seen in the adipose tissue of mice fed such a diet. Activated JNK impairs insulin signalling by phosphorylation of Ser307 in insulin receptor substrate-1 (IRS-1), preventing it from interacting with the activated insulin receptor and accelerating its proteasomal degradation. ${ }^{51}$ JNK may promote adipocyte expression of pro-inflammatory cytokines such as TNF $\alpha$ and MCP-1, at least in part, by phosphorylating c-Jun and thereby boosting AP-1 transcriptional activity. ${ }^{5-54}$ Phosphorylation of PPAR $\gamma$ by JNK diminishes its transcriptional activity, and this might account for JNK's ability to suppress expression of adiponectin, a hormone crucial for the maintenance of hepatic insulin sensitivity, control of gluconeogenesis and prevention of hepatic steatosis. ${ }^{55-59}$ And JNK mediates the suppressive effect of TNF $\alpha$ on $\beta$-klotho expression in adipocytes, an effect responsible for the decreased responsiveness of adipocytes to fibroblast growth factor21, a key stimulant to adiponectin expression. ${ }^{60}$

ASK1 is a prominent upstream activator of JNK (via MKK4) in adipocytes; its expression is upregulated in the visceral adipocytes of obese patients. ${ }^{61}$ The kinase activity of ASK1 is inhibited by its binding with the redox-modulated protein thioredoxin. ${ }^{62}{ }^{63}$ Oxidants such as hydrogen peroxide alter the structure of this protein by inducing formation of an intramolecular disulfide bridge; this structural alteration prevents the binding of thioredoxin to ASK1. ${ }^{6465}$ The reduced structure of thioredoxin is restored by thioredoxin reductase activity. ${ }^{65}$ When oxidant production frees ASK1 from its interaction with thioredoxin, ASK1 is susceptible to activation by signalling complexes formed after activation of toll receptor 4 (TLR4) or TNF $\alpha .{ }^{63}$ These complexes contain TRAF6 and TRAF2, respectively, which can bind with free ASK1 in such a way as to promote its homodimerisation, thereby unleashing its kinase activity. ${ }^{6366}$ Activation of TLR4-via binding to a saturated fatty acid/fetuin A complex ${ }^{67}$ as well as $\mathrm{TNF} \alpha$-mediated activation of its receptor on adipocytes, are prominent mechanisms for induction of insulin resistance in hypertrophied adipocytes. ${ }^{68}$ Activation of these receptors also boosts oxidant production, a prerequisite for their activation of ASK1 $1{ }^{63}{ }^{69}$ Suppression of this oxidant production, as by bilirubin or bilirubin mimesis, can therefore be expected to blunt activation of the ASK1-MEK4-JNK signalling pathway that is a crucial mediator of insulin resistance syndrome.

Consistent with this prediction, adipocyte-specific overexpression of HO-1, systemic induction HO-1, and oral administration of phycocyanin or whole spirulina have all been shown to promote proper adipocyte function and mitigate induction of metabolic syndrome in rodents fed high-fat or fructose-rich diets. ${ }^{70-75}$ Additionally, treatment with the broad-spectrum NADPH oxidase inhibitor apocynin attenuated development of metabolic syndrome in KKAy diabetes-prone mice. Oral administration of phycocyanin has a similar impact in these mice. ${ }^{76}$ The favourable impact of high-dose spirulina on insulin sensitivity in treated patients with HIV has been noted. ${ }^{77}$

\section{BILIRUBIN DIRECTLY PROTECTS TISSUES TARGETED BY METABOLIC SYNDROME}

Optimal adipocyte function helps to prevent hepatic steatosis by moderating free fatty acid flux to the liver when insulin is elevated and also by enabling appropriate adiponectin production. It is therefore notable that dietary spirulina has been found to decrease liver fat content and mitigate liver inflammation in rodent models of metabolic syndrome. ${ }^{78-80}$ Moreover, two open clinical trials in which spirulina was administered orally in centrally obese patients with non-alcoholic fatty liver disease have reported improved liver function (decreased serum hepatic enzymes and/or decrease liver fat as assessed by sonography). ${ }^{81}{ }^{82}$ In one of these trials, the patients ingested $6 \mathrm{~g}$ spirulina daily for 6 months; at the end of the study, liver enzymes had dropped by about a third, serum lipid profile had improved (lower triglycerides and LDL-C, higher HDL-C), insulin resistance assessed by HOMA had dropped by $20 \%$ and BMI had dropped by $8 \%$-changes that were all highly significant. ${ }^{82}$ Since the patients had not been asked to modify their diets or exercise habits, the observed weight loss conceivably could be attributable to an improvement in hypothalamic inflammation. Suppression of oxidant and cytokine production by infiltrating macrophages and Kupffer cells might also contribute to the improvement in liver function seen during spirulina administration, as activation of NADPH oxidase in these cells promotes the oxidant stress and inflammation that collaborates with lipid overload in induction of steatohepatitis. ${ }^{83-85}$ Moreover, activation of NADPH oxidase in stellate cells is a driver of the liver fibrosis that leads to end-stage cirrhosis. ${ }^{86}$

Metabolic syndrome also impairs vascular endothelial function-a likely reason why this syndrome collaborates with elevated low-density lipoprotein to promote atherogenesis and vascular events. ${ }^{87-89}$ Increased exposure to free fatty acids and proinflammatory cytokines, as well as decreased adiponectin levels, may play a role in mediating this endothelial dysfunction. Increased vascular expression and activity of NADPH oxidase is a feature of metabolic syndrome and a mediator of the associated endothelial dysfunction. ${ }^{90-93}$ Ingestion of spirulina or phycocyanin has been found to exert anti-atherosclerotic effects in rodent models. ${ }^{94-97}$

Prospective epidemiology links higher plasma bilirubin with lower risk for myocardial infarction, stroke, left ventricular hypertrophy (LVH) and heart failure, all of which are more common in those with metabolic syndrome. $^{98-101}$ Superior endothelial function may underlie much of this apparent protection, whereas 
diminished platelet aggregability may contribute to lower risk for vascular events, and better cardiac nitric oxide bioactivity stemming from control of NADPH oxidase-mediated oxidative stress may play a role in the diminished risk for LVH and heart failure associated with increased bilirubin. ${ }^{102-107}$

\section{BILIRUBIN AIDS PREVENTION OF TYPE 2 DIABETES AND OF DIABETIC COMPLICATIONS}

In pancreatic beta cells of patients with metabolic syndrome, an increase in Nox2-dependent oxidant production induced by joint overexposure to free fatty acids and glucose (glucolipotoxicity) can lead to a failure of glucose-stimulated insulin release and an upregulation of apoptosis that ushers in type 2 diabetes-which in turn sustains and exacerbates the glucolipotoxicity mediating beta-cell failure. ${ }^{108-112}$ This phenomenon may contribute to the inverse correlation of serum bilirubin with risk for type 2 diabetes. Indeed, oral biliverdin postpones onset of diabetes in $\mathrm{db} / \mathrm{db}$ mice. ${ }^{113}$ Moreover, hyperglycaemia-induced NADPH oxidase activation is a mediator of the microvascular complications of diabetes; in diabetics, serum bilirubin correlates inversely with risk for diabetic nephropathy, retinopathy and neuropathy. ${ }^{114-118}$ Most strikingly, when diabetics with documented GS were matched with other diabetics, not known to have GS, with respect to age, sex, duration of diabetes and severity of hyperglycaemia, those with GS were found to be less than a third as likely to develop nephropathy, retinopathy or coronary disease. ${ }^{119}$ Moreover, oral administration of biliverdin or of phycocyanin has been shown to prevent glomerulosclerosis in $\mathrm{db} / \mathrm{db}$ mice. ${ }^{1821}$

Hence, bilirubin or bilirubin mimesis may be beneficial with respect to the hypothalamic inflammation that promotes inappropriate weight gain, the adipocyte dysfunction that leads to metabolic syndrome once obesity has emerged, the hepatic and vascular pathology that often accompanies metabolic syndrome, the glucolipotoxicity-induced beta-cell dysfunction that can precipitate onset of type 2 diabetes in patients with metabolic syndrome, and the microvascular and macrovascular complications of diabetes. Moderate and safe downregulation of NADPH oxidase activity may thus have profound implications for preservation of metabolic and vascular health.

\section{Contributors All authors contributed to the final manuscript.}

Funding The authors have not declared a specific grant for this research from any funding agency in the public, commercial or not-for-profit sectors.

Competing interests JJD is author of The Salt Fix and Superfuel. MFM is an owner of a nutraceutical company and co-inventor and co-owner of a US patent covering nutraceutical uses of phycocyanobilin oligopeptides derived from cyanobacteria such as spirulina. JHO is an owner of a nutraceutical company.

Patient consent Not required.

Provenance and peer review Not commissioned; internally peer reviewed.

Open access This is an open access article distributed in accordance with the Creative Commons Attribution Non Commercial (CC BY-NC 4.0) license, which permits others to distribute, remix, adapt, build upon this work non-commercially, and license their derivative works on different terms, provided the original work is properly cited, appropriate credit is given, any changes made indicated, and the use is non-commercial. See: http://creativecommons.org/licenses/by-nc/4.0/

\section{REFERENCES}

1. Kadakol A, Ghosh SS, Sappal BS, et al. Genetic lesions of bilirubin uridine-diphosphoglucuronate glucuronosyltransferase (UGT1A1) causing Crigler-Najjar and Gilbert syndromes: correlation of genotype to phenotype. Hum Mutat 2000;16:297-306.

2. McCarty MF. Serum bilirubin may serve as a marker for increased heme oxygenase activity and inducibility in tissues - a rationale for the versatile health protection associated with elevated plasma bilirubin. Med Hypotheses 2013;81:607-10.

3. McCarty MF. "latrogenic Gilbert syndrome" - a strategy for reducing vascular and cancer risk by increasing plasma unconjugated bilirubin. Med Hypotheses 2007;69:974-94.

4. Vítek L. Bilirubin and atherosclerotic diseases. Physiol Res 2017;66(Suppl 1):S11-20.

5. Maruhashi T, Soga J, Fujimura N, et al. Hyperbilirubinemia, augmentation of endothelial function, and decrease in oxidative stress in Gilbert syndrome. Circulation 2012;126:598-603.

6. Horsfall LJ, Nazareth I, Pereira SP, et al. Gilbert's syndrome and the risk of death: a population-based cohort study. J Gastroenterol Hepatol 2013;28:1643-7.

7. Lanone S, Bloc S, Foresti R, et al. Bilirubin decreases nos2 expression via inhibition of $\mathrm{NAD}(\mathrm{P}) \mathrm{H}$ oxidase: implications for protection against endotoxic shock in rats. The FASEB Journal 2005;19:1890-2.

8. Matsumoto $\mathrm{H}$, Ishikawa $\mathrm{K}$, Itabe $\mathrm{H}$, et al. Carbon monoxide and bilirubin from heme oxygenase-1 suppresses reactive oxygen species generation and plasminogen activator inhibitor-1 induction. Mol Cell Biochem 2006;291:21-8.

9. Jiang F, Roberts SJ, Datla S, et al. NO modulates NADPH oxidase function via heme oxygenase-1 in human endothelial cells. Hypertension 2006;48:950-7.

10. Datla SR, Dusting GJ, Mori TA, et al. Induction of heme oxygenase-1 in vivo suppresses NADPH oxidase derived oxidative stress. Hypertension 2007;50:636-42.

11. Basuroy S, Bhattacharya S, Leffler CW, et al. Nox4 NADPH oxidase mediates oxidative stress and apoptosis caused by TNF-alpha in cerebral vascular endothelial cells. Am J Physiol Cell Physiol 2009;296:C422-32.

12. DiNicolantonio JJ, McCarty MF, Glassman C. Angiotensin antagonist drugs as "source antioxidants" - down-regulation of NADPH oxidase activation mediates many of their protective benefits, independent of hypertension control. Oxid Antioxid Med Sci 2015;4:1-16.

13. Bindoli A, Rigobello MP. Principles in redox signaling: from chemistry to functional significance. Antioxid Redox Signal 2013;18:1557-93.

14. Ferrer-Sueta G, Campolo N, Trujillo M, et al. Biochemistry of peroxynitrite and protein tyrosine nitration. Chem Rev 2018;118:1338-408.

15. Adam O, Laufs U. Rac1-mediated effects of HMG-CoA reductase inhibitors (statins) in cardiovascular disease. Antioxid Redox Signal 2014;20:1238-50.

16. Nguyen Dinh Cat A, Montezano AC, Burger D, et al. Angiotensin II, $\mathrm{NADPH}$ oxidase, and redox signaling in the vasculature. Antioxid Redox Signal 2013;19:1110-20.

17. Dekker D, Dorresteijn MJ, Pijnenburg M, et al. The bilirubinincreasing drug atazanavir improves endothelial function in patients with type 2 diabetes mellitus. Arterioscler Thromb Vasc Biol 2011;31:458-63.

18. Fujii M, Inoguchi T, Sasaki S, et al. Bilirubin and biliverdin protect rodents against diabetic nephropathy by downregulating $\mathrm{NAD}(\mathrm{P}) \mathrm{H}$ oxidase. Kidney Int 2010;78:905-19.

19. McCarty MF. Clinical potential of Spirulina as a source of phycocyanobilin. J Med Food 2007;10:566-70.

20. Terry MJ, Maines MD, Lagarias JC. Inactivation of phytochromeand phycobiliprotein-chromophore precursors by rat liver biliverdin reductase. J Biol Chem 1993;268:26099-106.

21. Zheng J, Inoguchi T, Sasaki S, et al. Phycocyanin and phycocyanobilin from Spirulina platensis protect against diabetic nephropathy by inhibiting oxidative stress. Am J Physiol Regul Integr Comp Physiol 2013;304:R110-20.

22. Romay C, Gonzalez R, Ledon N, et al. Rimbau V. C-phycocyanin: a biliprotein with antioxidant, anti-inflammatory and neuroprotective effects. Curr Protein Pept Sci 2003;4:207-16. 
23. Liu Q, Huang $\mathrm{Y}$, Zhang R, et al. Medical application of spirulina platensis derived C-phycocyanin. Evid Based Complement Alternat Med 2016;2016:7803846.

24. Seyed Khoei N, Grindel A, Wallner M, et al. Mild hyperbilirubinaemia as an endogenous mitigator of overweight and obesity: implications for improved metabolic health. Atherosclerosis 2018;269:306-11.

25. Wallner M, Antl N, Rittmannsberger B, et al. Anti-genotoxic potential of bilirubin in vivo: damage to DNA in hyperbilirubinemic human and animal models. Cancer Prev Res 2013;6:1056-63.

26. Liu J, Dong H, Zhang Y, et al. Bilirubin increases insulin sensitivity by regulating cholesterol metabolism, adipokines and PPAR $\gamma$ Levels. Sci Rep 2015;5:9886.

27. McCarty MF. Does elevated bilirubin aid weight control by preventing development of hypothalamic leptin resistance? Med Hypotheses 2018.

28. Münzberg H, Flier JS, Bjørbæk C. Region-specific leptin resistance within the hypothalamus of diet-induced obese mice. Endocrinology 2004;145:4880-9.

29. Zhou Y, Rui L. Leptin signaling and leptin resistance. Front Med 2013;7:207-22.

30. Jung $\mathrm{CH}, \mathrm{Kim}$ M-S. Molecular mechanisms of central leptin resistance in obesity. Arch Pharm Res 2013;36:201-7.

31. Picardi PK, Caricilli AM, de Abreu LL, et al. Modulation of hypothalamic PTP1B in the TNF-alpha-induced insulin and leptin resistance. FEBS Lett 2010;584:3179-84.

32. Valdearcos M, Robblee MM, Benjamin DI, et al. Microglia dictate the impact of saturated fat consumption on hypothalamic inflammation and neuronal function. Cell Rep 2014;9:2124-38.

33. Valdearcos M, Xu AW, Koliwad SK. Hypothalamic inflammation in the control of metabolic function. Annu Rev Physiol 2015;77:131-60.

34. André C, Guzman-Quevedo O, Rey C, et al. Inhibiting microglia expansion prevents diet-induced hypothalamic and peripheral inflammation. Diabetes 2017;66:908-19.

35. Qin L, Li G, Qian X, et al. Interactive role of the toll-like receptor 4 and reactive oxygen species in LPS-induced microglia activation. Glia 2005;52:78-84.

36. Sorce S, Stocker R, Seredenina T, et al. NADPH oxidases as drug targets and biomarkers in neurodegenerative diseases: what is the evidence? Free Radical Biology and Medicine 2017;112:387-96.

37. McCarty MF, Barroso-Aranda J, Contreras F. Oral phycocyanobilin may diminish the pathogenicity of activated brain microglia in neurodegenerative disorders. Med Hypotheses 2010;74:601-5.

38. Talior I, Tennenbaum T, Kuroki T, et al. PKC-delta-dependent activation of oxidative stress in adipocytes of obese and insulinresistant mice: role for NADPH oxidase. Am J Physiol Endocrinol Metab 2005;288:E405-11.

39. Furukawa S, Fujita T, Shimabukuro M, et al. Increased oxidative stress in obesity and its impact on metabolic syndrome. J Clin Invest 2004;114:1752-61.

40. Han CY, Umemoto T, Omer M, et al. NADPH oxidase-derived reactive oxygen species increases expression of monocyte chemotactic factor genes in cultured adipocytes. J Biol Chem 2012;287:10379-93.

41. Lin L, Pang W, Chen K, et al. Adipocyte expression of PU.1 transcription factor causes insulin resistance through upregulation of inflammatory cytokine gene expression and ROS production. Am J Physiol Endocrinol Metab 2012;302:E1550-59.

42. Jankovic A, Korac A, Buzadzic B, et al. Redox implications in adipose tissue (dys)function - a new look at old acquaintances. Redox Biol 2015;6:19-32.

43. Prokudina ES, Maslov LN, Ivanov VV, et al. The role of reactive oxygen species in the pathogenesis of adipocyte dysfunction in metabolic syndrome. Prospects of pharmacological correction. Annals of the Russian academy of medical sciences 2017;72:11-16

44. Nano J, Muka T, Cepeda M, et al. Association of circulating total bilirubin with the metabolic syndrome and type 2 diabetes: a systematic review and meta-analysis of observational evidence. Diabetes Metab 2016;42:389-97.

45. Lee MJ, Jung $\mathrm{CH}$, Kang YM, et al. Serum bilirubin as a predictor of incident metabolic syndrome: a 4-year retrospective longitudinal study of 6205 initially healthy Korean men. Diabetes Metab 2014; 40:305-9.

46. Huang SS, Chan WL, Leu HB, et al. Serum bilirubin levels predict future development of metabolic syndrome in healthy middle-aged nonsmoking men. Am J Med 2015;128:1138.e35-41.

47. Den Hartigh LJ, Omer M, Goodspeed L, et al. Adipocyte-specific deficiency of NADPH oxidase 4 delays the onset of insulin resistance and attenuates adipose tissue inflammation in obesity. Arterioscler Thromb Vasc Biol 2017;37:466-75.
48. Blüher M, Bashan N, Shai I, et al. Activated Ask1-MKK4-p38MAPK JNK stress signaling pathway in human omental fat tissue may link macrophage infiltration to whole-body Insulin sensitivity. The Journal of Clinical Endocrinology \& Metabolism 2009;94:2507-15.

49. Hirosumi J, Tuncman G, Chang L, et al. A central role for JNK in obesity and insulin resistance. Nature 2002;420:333-6.

50. Zhang X, Xu A, Chung SK, et al. Selective inactivation of c-Jun $\mathrm{NH} 2$-terminal kinase in adipose tissue protects against dietinduced obesity and improves insulin sensitivity in both liver and skeletal muscle in mice. Diabetes 2011;60:486-95.

51. Aguirre V, Uchida T, Yenush L, et al. The c-Jun NH(2)-terminal kinase promotes insulin resistance during association with insulin receptor substrate-1 and phosphorylation of Ser(307). J Biol Chem 2000;275:9047-54.

52. Sutcliffe AM, Clarke DL, Bradbury DA, et al. Transcriptional regulation of monocyte chemotactic protein-1 release by endothelin-1 in human airway smooth muscle cells involves NF-KB and AP-1. Br J Pharmacol 2009;157:436-50.

53. Newell CL, Deisseroth AB, Lopez-Berestein G. Interaction of nuclear proteins with an AP-1/CRE-like promoter sequence in the human TNF-alpha gene. J Leukoc Biol 1994;56:27-35.

54. Karin $\mathrm{M}$. The regulation of AP-1 activity by mitogen-activated protein kinases. J Biol Chem 1995;270:16483-6.

55. Camp HS, Tafuri SR, Leff T. c-Jun N-terminal kinase phosphorylates peroxisome proliferator-activated receptor-gamma1 and negatively regulates its transcriptional activity. Endocrinology 1999;140:392-7.

56. Kim KY, Kim JK, Jeon JH, et al. c-Jun N-terminal kinase is involved in the suppression of adiponectin expression by TNF-alpha in 3T3L1 adipocytes. Biochem Biophys Res Commun 2005;327:460-7.

57. Achari AE, Jain SK, Adiponectin JSK. Adiponectin, a therapeutic target for obesity, diabetes, and endothelial dysfunction. Int $\mathrm{J} \mathrm{Mol}$ Sci 2017;18:E1321

58. Zhou $\mathrm{H}$, Song $\mathrm{X}$, Briggs $\mathrm{M}$, et al. Adiponectin represses gluconeogenesis independent of insulin in hepatocytes. Biochem Biophys Res Commun 2005;338:793-9.

59. Nawrocki AR, Rajala MW, Tomas E, et al. Mice lacking adiponectin show decreased hepatic insulin sensitivity and reduced responsiveness to peroxisome proliferator-activated receptor gamma agonists. J Biol Chem 2006;281:2654-60.

60. Díaz-Delfín J, Hondares E, Iglesias R, et al. TNF- $\alpha$ represses $\beta$-Klotho expression and impairs FGF21 action in adipose cells: involvement of JNK1 in the FGF21 pathway. Endocrinology 2012;153:4238-45.

61. Haim Y, Blüher M, Konrad D, et al. ASK1 (MAP3K5) is transcriptionally upregulated by E2F1 in adipose tissue in obesity, molecularly defining a human dys-metabolic obese phenotype. Mol Metab 2017;6:725-36.

62. Saitoh M, Nishitoh H, Fujii M, et al. Mammalian thioredoxin is a direct inhibitor of apoptosis signal-regulating kinase (ASK) 1. Embo J 1998;17:2596-606.

63. Liu H, Nishitoh $\mathrm{H}$, Ichijo $\mathrm{H}$, et al. Activation of apoptosis signalregulating kinase 1 (ASK1) by tumor necrosis factor receptorassociated factor 2 requires prior dissociation of the ASK1 inhibitor thioredoxin. Mol Cell Biol 2000;20:2198-208.

64. Fujino G, Noguchi T, Takeda K, et al. Thioredoxin and protein kinases in redox signaling. Semin Cancer Biol 2006;16:427-35.

65. Mahmood DF, Abderrazak A, El Hadri K, et al. The thioredoxin system as a therapeutic target in human health and disease. Antioxid Redox Signal 2013;19:1266-303.

66. Matsuzawa A, Saegusa K, Noguchi T, et al. ROS-dependent activation of the TRAF6-ASK1-p38 pathway is selectively required for TLR4-mediated innate immunity. Nat Immunol 2005;6:587-92.

67. Pal D, Dasgupta S, Kundu R, et al. Fetuin-A acts as an endogenous ligand of TLR4 to promote lipid-induced insulin resistance. Nat Med 2012;18:1279-85

68. Qi C, Pekala PH. Tumor necrosis factor-alpha-induced insulin resistance in adipocytes. Proc Soc Exp Biol Med 2000;223:128-35.

69. Gotoh Y, Cooper JA. Reactive oxygen species- and dimerizationinduced activation of apoptosis signal-regulating kinase 1 in umor necrosis factor-alpha signal transduction. J Biol Chem 1998;273:17477-82.

70. Burgess A, Li M, Vanella L, et al. Adipocyte heme oxygenase-1 induction attenuates metabolic syndrome in both male and female obese mice. Hypertension 2010;56:1124-30.

71. Tu TH, Joe Y, Choi HS, et al. Induction of heme oxygenase-1 with hemin reduces obesity-induced adipose tissue inflammation via adipose macrophage phenotype switching. Mediators Inflamm 2014:2014:290708.

72. Khitan Z, Harsh M, Sodhi K. HO-1 upregulation attenuates adipocyte dysfunction, obesity, and isoprostane levels in mice fed high fructose diets. J Nutr Metab 2014;2014:980547-13. 
73. Cao J, Peterson SJ, Sodhi K, et al. Heme oxygenase gene targeting to adipocytes attenuates adiposity and vascular dysfunction in mice fed a high-fat diet. Hypertension 2012;60:467-75.

74. Ichimura M, Kato S, Tsuneyama K, et al. Phycocyanin prevents hypertension and low serum adiponectin level in a rat model of metabolic syndrome. Nutr Res 2013;33:397-405.

75. Hozayen WG, Mahmoud AM, Soliman HA, et al. Spirulina versicolor improves insulin sensitivity and attenuates hyperglycemia-mediated oxidative stress in fructose-fed rats. J Intercult Ethnopharmacol 2016;5:57-64.

76. Ou Y, Lin L, Yang X, et al. Antidiabetic potential of phycocyanin: effects on KKAy mice. Pharm Biol 2013;51:539-44

77. Marcel AK, Ekali LG, Eugene S, et al. The effect of Spirulina platensis versus soybean on insulin resistance in HIV-infected patients: a randomized pilot study. Nutrients 2011;3:712-24.

78. González de Rivera C, Miranda-Zamora R, Díaz-Zagoya JC, et al. Preventive effect of Spirulina maxima on the fatty liver induced by a fructose-rich diet in the rat, a preliminary report. Life Sci 1993;53:57-61.

79. Moura LP, Puga GM, Beck WR, et al. Exercise and spirulina control non-alcoholic hepatic steatosis and lipid profile in diabetic Wistar rats. Lipids Health Dis 2011;10:77.

80. Fujimoto M, Tsuneyama K, Fujimoto T, et al. Spirulina improves non-alcoholic steatohepatitis, visceral fat macrophage aggregation, and serum leptin in a mouse model of metabolic syndrome. Digestive and Liver Disease 2012;44:767-74

81. Ferreira-Hermosillo A, Torres-Duran PV, Juarez-Oropeza MA. Hepatoprotective effects of Spirulina maxima in patients with non-alcoholic fatty liver disease: a case series. J Med Case Rep 2010;4:103.

82. Mazokopakis EE, Papadomanolaki MG, Fousteris AA, et al. The hepatoprotective and hypolipidemic effects of Spirulina (Arthrospira platensis) supplementation in a Cretan population with non-alcoholic fatty liver disease: a prospective pilot study. Ann Gastroenterol 2014;27:387-94.

83. Wenfeng Z, Yakun W, Di M, et al. Kupffer cells: increasingly significant role in nonalcoholic fatty liver disease. Ann Hepatol 2014;13:489-95.

84. Kim SY, Jeong JM, Kim SJ, et al. Pro-inflammatory hepatic macrophages generate ROS through NADPH oxidase 2 via endocytosis of monomeric TLR4-MD2 complex. Nat Commun 2017;8:2247

85. Del Ben M, Polimeni L, Carnevale R, et al. NOX2-generated oxidative stress is associated with severity of ultrasound liver steatosis in patients with non-alcoholic fatty liver disease. BMC Gastroenterol 2014;14:81.

86. Liang S, Kisseleva T, Brenner DA. The role of NADPH oxidases (NOXs) in liver fibrosis and the activation of myofibroblasts. Front Physiol 2016;7:17.

87. Tziomalos K, Athyros VG, Karagiannis A, et al. Endothelial dysfunction in metabolic syndrome: prevalence, pathogenesis and management. Nutr Metab Cardiovasc Dis 2010;20:140-6.

88. Meyers MR, Gokce N. Endothelial dysfunction in obesity: etiological role in atherosclerosis. Curr Opin Endocrinol Diabetes Obes 2007:14:365-9

89. Prieto D, Contreras C, Sanchez A. Endothelial dysfunction, obesity and insulin resistance. Curr Vasc Pharmacol 2014;12:412-26.

90. Galili O, Versari D, Sattler KJ, et al. Early experimental obesity is associated with coronary endothelial dysfunction and oxidative stress. Am J Physiol Heart Circ Physiol 2007;292:H904-11.

91. Roberts CK, Barnard RJ, Sindhu RK, et al. Oxidative stress and dysregulation of $\mathrm{NAD}(\mathrm{P}) \mathrm{H}$ oxidase and antioxidant enzymes in dietinduced metabolic syndrome. Metabolism 2006;55:928-34.

92. Du J, Fan LM, Mai A, et al. Crucial roles of Nox2-derived oxidative stress in deteriorating the function of insulin receptors and endothelium in dietary obesity of middle-aged mice. $\mathrm{Br} J$ Pharmacol 2013;170:1064-77.

93. Qin Z, Hou X, Weisbrod RM, et al. Nox2 mediates high fat high sucrose diet-induced nitric oxide dysfunction and inflammation in aortic smooth muscle cells. J Mol Cell Cardiol 2014;72:56-63.

94. Riss J, Décordé K, Sutra T, et al. Phycobiliprotein C-phycocyanin from Spirulina platensis is powerfully responsible for reducing oxidative stress and NADPH oxidase expression induced by an atherogenic diet in hamsters. J Agric Food Chem 2007:55:7962-7.

95. Vidé J, Virsolvy A, Romain C, et al. Dietary silicon-enriched spirulina improves early atherosclerosis markers in hamsters on a high-fat diet. Nutrition 2015;31:1148-54.
96. Li B, Chu XM, Xu YJ, et al. CD59 underlines the antiatherosclerotic effects of C-phycocyanin on mice. Biomed Res Int 2013;2013:729413-.

97. Strasky Z, Zemankova L, Nemeckova I, et al. Spirulina platensis and phycocyanobilin activate atheroprotective heme oxygenase-1: a possible implication for atherogenesis. Food Funct 2013;4:1586-94.

98. Horsfall LJ, Nazareth I, Petersen I. Cardiovascular events as a function of serum bilirubin levels in a large, statin-treated cohort. Circulation 2012;126:2556-64.

99. Marconi VC, Duncan MS, So-Armah K, et al. Bilirubin is inversely associated with cardiovascular disease among HIV-positive and HIV-negative individuals in VACS (Veterans Aging Cohort Study). J Am Heart Assoc 2018;7:e007792.

100. Zhou T, Chen X, Li Z, et al. Relationship between serum bilirubin and left ventricular hypertrophy in patients with essential hypertension. PLoS One 2015;10:e0125275.

101. Kimm H, Yun JE, Jo J, et al. Low serum bilirubin level as an independent predictor of stroke incidence: a prospective study in Korean men and women. Stroke 2009;40:3422-7.

102. Kundur AR, Singh I, Bulmer AC. Bilirubin, platelet activation and heart disease: a missing link to cardiovascular protection in Gilbert's syndrome? Atherosclerosis 2015;239:73-84.

103. Kundur AR, Santhakumar AB, Bulmer AC, et al. Mildly elevated unconjugated bilirubin is associated with reduced platelet activation-related thrombogenesis and inflammation in Gilbert's syndrome. Platelets 2017;28:779-85.

104. Massion PB, Balligand JL. Relevance of nitric oxide for myocardial remodeling. Curr Heart Fail Rep 2007;4:18-25.

105. Wollert KC, Drexler H. Regulation of cardiac remodeling by nitric oxide: focus on cardiac myocyte hypertrophy and apoptosis. Heart Fail Rev 2002;7:317-25.

106. Takimoto E, Kass DA. Role of oxidative stress in cardiac hypertrophy and remodeling. Hypertension 2007;49:241-8.

107. Krüger M, Kötter S, Grützner A, et al. Protein kinase G modulates human myocardial passive stiffness by phosphorylation of the titin springs. Circ Res 2009;104:87-94.

108. Inoguchi T, Nawata $\mathrm{H}$. $\mathrm{NAD}(\mathrm{P}) \mathrm{H}$ oxidase activation: a potential target mechanism for diabetic vascular complications, progressive beta-cell dysfunction and metabolic syndrome. Curr Drug Targets 2005;6:495-501.

109. Guichard C, Moreau R, Pessayre D, et al. NOX family NADPH oxidases in liver and in pancreatic islets: a role in the metabolic syndrome and diabetes? Biochem Soc Trans 2008;36(Pt 5):920-9.

110. McCarty MF, Barroso-Aranda J, Contreras F. NADPH oxidase mediates glucolipotoxicity-induced beta cell dysfunction-clinical implications. Med Hypotheses 2010;74:596-600.

111. Yuan $\mathrm{H}$, Zhang $\mathrm{X}$, Huang $\mathrm{X}$, et al. NADPH oxidase 2-derived reactive oxygen species mediate FFAs-induced dysfunction and apoptosis of $\beta$-cells via JNK, p38 MAPK and p53 pathways. PLoS One 2010;5:e15726.

112. Mohammed AM, Kowluru A. Activation of apocynin-sensitive NADPH oxidase (Nox2) activity in INS-1 832/13 cells under glucotoxic conditions. Islets 2013:5:129-31.

113. Ikeda $\mathrm{N}$, Inoguchi $\mathrm{T}$, Sonoda $\mathrm{N}$, et al. Biliverdin protects against the deterioration of glucose tolerance in $\mathrm{db} / \mathrm{db}$ mice. Diabetologia 2011:54:2183-91.

114. Sedeek M, Montezano AC, Hebert RL, et al. Oxidative stress, Nox isoforms and complications of diabetes - potential targets for novel therapies. J Cardiovasc Trans/ Res 2012;5:509-18.

115. Ha H, Hwang IA, Park JH, et al. Role of reactive oxygen species in the pathogenesis of diabetic nephropathy. Diabetes Res Clin Pract 2008;82(Suppl 1):S42-5

116. Koulis C, Watson AM, Gray SP, et al. Linking RAGE and Nox in diabetic micro- and macrovascular complications. Diabetes Metab 2015;41:272-81.

117. Zhu B, Wu X, Bi Y, et al. Effect of bilirubin concentration on the risk of diabetic complications: a meta-analysis of epidemiologic studies. Sci Rep 2017;7:41681

118. Inoguchi $\mathrm{T}$, Tsubouchi $\mathrm{H}$, Etoh $\mathrm{T}$, et al. A possible target of antioxidative therapy for diabetic vascular complications-vascular NAD(P)H oxidase. Curr Med Chem 2003;10:1759-64.

119. Inoguchi T, Sasaki S, Kobayashi K, et al. Relationship between Gilbert syndrome and prevalence of vascular complications in patients with diabetes. JAMA 2007;298:1396-400. 